\title{
Study on magnetostriction characteristics under different measurement conditions under an externally compressive stress
}

\author{
Meilin Lu', Lanrong Liu², Chao Fan ${ }^{3}$, Bin Wang ${ }^{4}$ \\ ${ }^{1,2}$ Institute of Power Transmission and Transformation Technology, Baobian Electric, Baoding, China \\ ${ }^{3}$ Global Energy Interconnection Research Institute, Beijing, 100124, China \\ ${ }^{4}$ State Grid Jinhua Power Supply Company, Jinhua, 321001, China \\ ${ }^{1}$ Corresponding author

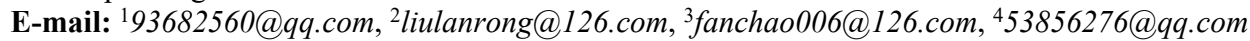

Received 4 January 2022; received in revised form 14 January 2022; accepted 25 January 2022 DOI https://doi.org/10.21595/vp.2022.22386

Copyright $(C) 222$ Meilin Lu, et al. This is an open access article distributed under the Creative Commons Attribution License, which permits unrestricted use, distribution, and reproduction in any medium, provided the original work is properly cited.

\begin{abstract}
The measurement of magnetostriction characteristics of grain-oriented electrical steel strip under an external compressive stress has always been a main focus in the process of magnetostriction measurement. There are difficulties in the measurement of magnetostriction, especially under compressive stress, mainly because the thickness of test specimen is small, and the test specimen is very easy to deform under the compressive stress. A weight should be placed on the test specimen to prevent a deformation of the test specimen when the measurement of magnetostriction characteristics under an externally compressive stress according to the IEC/TR 62581:2010. But how much weight and how to place aren't concerned in IEC standard. In this paper, different weights were placed on the grain-oriented electrical steel test specimen under external compressive stress and zero stress. Through analyzed the measured magnetostriction data under different weights to determine the optimal measurement method of grain-oriented electrical steel strip under compressive stress and zero stress. The purpose of this paper is to find the most accurate and high reproducibility measurement method of magnetostriction, which can truly reflect the magnetostriction performance of grain-oriented electrical steel.
\end{abstract}

Keywords: magnetostriction characteristics, compressive stress, measurement method, different weights.

\section{Introduction}

The magnetostriction characteristics of grain-oriented electrical steel are the main reason to make the vibration and acoustic of electrical equipment such as transformer and reactor. In order to better study the characteristics of grain-oriented electrical steel in reactor, the main research in this paper is the magnetostriction characteristics of grain-oriented electrical steel under compressive stress.

\section{Magnetostriction measurement system}

The BROCKHAUSE MST magnetostriction measurement system was used in this paper, as shown in Fig. 1. The measurement system includes power supply system, magnetic circuit which composed of yokes and windings, laser transmitting and receiving system, vibration-free table and applied stress device. The emission frequency of the laser transmitter is $100 \mathrm{~Hz}$ and the test resolution reaches $10 \mathrm{~nm} / \mathrm{m}$.

The effective size of the test specimen is $100 \mathrm{~mm} \times 500 \mathrm{~mm}$. The surface of the test specimen shall be flat and smooth without damage. The test specimen was placed in the gap between the two yokes of the measurement system. The laser beam shall be parallel to the axis of the windings and yokes in order to prevent measurement offsets due to vertical and lateral vibrations of the test specimen. The measuring device calculates the deformation of the test specimen by detecting the 
change of the distance between the laser emission and the laser target.

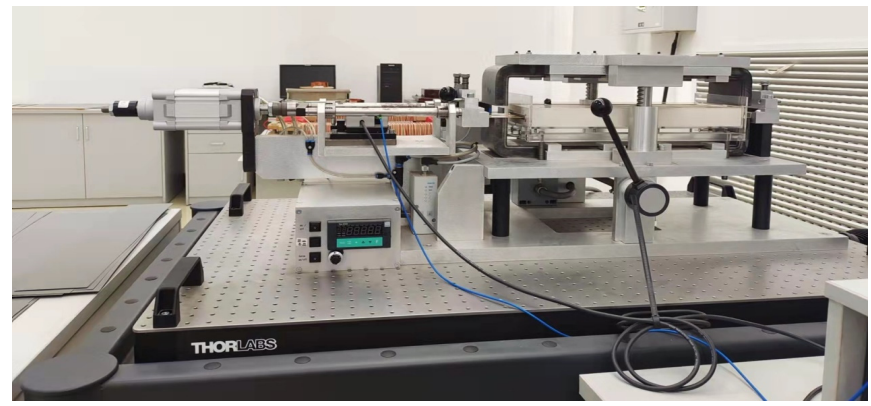

Fig. 1. The magnetostriction measurement system

The size of the test specimen 30SQGD105 is $100 \mathrm{~mm} \times 600 \mathrm{~mm}$, and its Rolling Direction and Transverse Direction are as Fig. 2.

The epoxy plates placed on the test specimen between the two ends and the free deformation distance should be enough for the magnetostriction measurement and the blocks were between the upper yoke and the plate as Fig. 3.

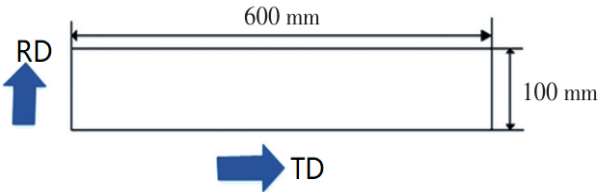

Fig. 2. The test specimen (30SQGD105)

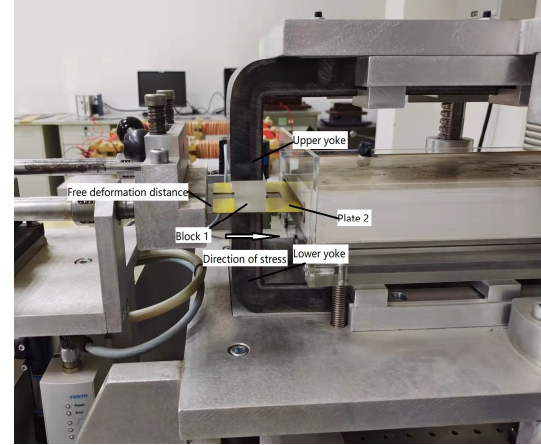

Fig. 3. Measurement process under compressive stress

\section{Measurement process and results}

\subsection{Magnetostriction measurement without stress}

The grain-oriented electrical steel (30SQGD105) test specimen were measured under five measurement conditions as Table 1 .

The characters of the plates and blocks placed on the test specimen are as Table 2 .

Table 1. Five different measurement conditions

\begin{tabular}{|c|l|}
\hline Case 1 & \multicolumn{1}{c|}{ One end is fixed and one end was suspended } \\
\hline Case 2 & $\begin{array}{l}\text { One end is fixed and one end was suspended, an epoxy plate (Plate 1) was placed on the } \\
\text { test specimen }\end{array}$ \\
\hline Case 3 & $\begin{array}{l}\text { One end is fixed and one end was suspended, an epoxy plate (Plate 2) was placed on the } \\
\text { test specimen }\end{array}$ \\
\hline Case 4 & $\begin{array}{l}\text { One end is fixed and one end was suspended, an epoxy plate (Plate 2) and two epoxy } \\
\text { blocks (Block 1) were placed on the test specimen }\end{array}$ \\
\hline Case 5 & $\begin{array}{l}\text { One end is fixed and one end was suspended, an epoxy plate (Plate 2) and two epoxy } \\
\text { blocks (Block 2) were placed on the test specimen }\end{array}$ \\
\hline
\end{tabular}

Magnetic flux density $1.2 \mathrm{~T}$ was taken as the comparison point for this data statistics. Three or four times measurements were carried out under each measurement condition, the average value 
was taken as the magnetostriction parameter. The results are shown in Table 3.

Table 2. The characters of the plates and blocks

\begin{tabular}{|c|c|c|c|c|}
\hline & Plate 1 & Plate 2 & Block 1 & Block 2 \\
\hline Weight $(\mathrm{g})$ & 38.4 & 56.67 & 25.9 & 69.8 \\
\hline Length $(\mathrm{mm})$ & 509 & 514 & 40 & 65 \\
\hline Width $(\mathrm{mm})$ & 100 & 100 & 24 & 40 \\
\hline Height $(\mathrm{mm})$ & 1 & 1.16 & 23 & 23 \\
\hline \multicolumn{7}{|l}{ Note: The surfaces of the plates and blocks are smooth and flat } \\
\hline
\end{tabular}

Table 3. Comparison of measured data under different measurement conditions

\begin{tabular}{|l|c|c|c|c|}
\hline & $\lambda_{z-p}[\mathrm{~nm} / \mathrm{m}]$ & $\lambda_{p-p}[\mathrm{~nm} / \mathrm{m}]$ & AWV $[\mathrm{dBA}]$ & $P_{s}[\mathrm{~W} / \mathrm{kg}]$ \\
\hline Case 1 & 15455.32 & 15513.47 & 82.67422 & 2.460704 \\
\hline Case 2 & 15423.66 & 15476.86 & 82.64047 & 2.458887 \\
\hline Case 3 & 15413.03 & 15452.25 & 82.53016 & 2.453194 \\
\hline Case 4 & 15403.96 & 15452.15 & 82.57334 & 2.453172 \\
\hline Case 5 & 12882.31 & 13036.99 & 81.53271 & 2.460597 \\
\hline
\end{tabular}

From the above table, it can be concluded that when different weights placed on the test specimen, the magnetostriction data of grain-oriented electrical steel, $\lambda_{z-p}[\mathrm{~nm} / \mathrm{m}], \lambda_{P-P}[\mathrm{~nm} / \mathrm{m}]$ and AWV [DBA] decrease with the increase of weight, and $P_{S}[\mathrm{w} / \mathrm{kg}]$ basically does not change.

\section{Magnetostriction measurement under compressive stress}

There are three measurement conditions were measured as Table 4.

Table 4. Three different measurement conditions under compressive stress

\begin{tabular}{|c|l|}
\hline Case 1 & $\begin{array}{l}\text { Two ends fixed, an epoxy plate (Plate 2) and two epoxy blocks (Block 1) were placed on } \\
\text { the test specimen }\end{array}$ \\
\hline Case 2 & $\begin{array}{l}\text { Two ends fixed, an epoxy plate (Plate 2) and two epoxy blocks (Block 2) were placed on } \\
\text { the test specimen }\end{array}$ \\
\hline Case 3 & $\begin{array}{l}\text { Two ends fixed, an epoxy plate (Plate 2) and two epoxy blocks (Block 2) were placed on } \\
\text { the test specimen, put down the upper yoke to the blocks }\end{array}$ \\
\hline
\end{tabular}

The magnetostriction parameters, such as zero-to-peak value $\lambda_{z-p}$ and peak-to-peak value $\lambda_{p-p}$, under different compressive stress were obtained through repeated measurements, ensuring the repeatability. The magnetostriction parameters on $1.2 \mathrm{~T}$ are shown in Tables 5-6, and Fig. 4(a-d).

Table 5. Comparison of $\lambda_{z-p}$ under different compressive stress, Unit: $\mathrm{nm} / \mathrm{m}$

\begin{tabular}{|c|c|c|c|c|c|c|c|c|}
\hline Stress & $0 \mathrm{MPa}$ & $-2 \mathrm{MPa}$ & $-4 \mathrm{MPa}$ & $-5.5 \mathrm{MPa}$ & $-7 \mathrm{MPa}$ & $-8 \mathrm{MPa}$ & $-9 \mathrm{MPa}$ & $-10 \mathrm{MPa}$ \\
\hline Case 1 & 15403.9 & 4755.50 & 4678.91 & 4605.59 & 4424.76 & 4534.75 & 4781.61 & 4868.74 \\
\hline Case 2 & 12882.3 & 5713.98 & 4834.28 & 5080.79 & 5002.01 & 5191.09 & 5085.79 & 4948.44 \\
\hline Case 3 & 8701.98 & 3377.75 & 3139.46 & 3002.79 & 2812.38 & 2867.37 & 2990.81 & 2934.37 \\
\hline
\end{tabular}

Table 6. Comparison of $\lambda_{p-p}$ under different compressive stress, Unit: $\mathrm{nm} / \mathrm{m}$

\begin{tabular}{|c|c|c|c|c|c|c|c|c|}
\hline Stress & $0 \mathrm{MPa}$ & $-2 \mathrm{MPa}$ & $-4 \mathrm{MPa}$ & $-5.5 \mathrm{MPa}$ & $-7 \mathrm{MPa}$ & $-8 \mathrm{MPa}$ & $-9 \mathrm{MPa}$ & $-10 \mathrm{MPa}$ \\
\hline Case 1 & 15452.2 & 5009.23 & 5160.49 & 5083.52 & 5093.24 & 5143.44 & 5259.81 & 5390.52 \\
\hline Case 2 & 13036.9 & 5916.56 & 5089.91 & 5269.38 & 5289.89 & 5456.34 & 5364.79 & 5229.01 \\
\hline Case 3 & 8726.08 & 3504.61 & 3580.25 & 3041.76 & 2846.62 & 2871.72 & 2929.91 & 2995.26 \\
\hline
\end{tabular}

It can be concluded from the figures and tables that when a certain weight was placed on the test specimen, the magnetostriction of the grain-oriented electrical steel was decrease with the increase of the weights under zero stress conditions.

It is well know that mechanical stress in grain-oriented electrical steel has a strong influence 
on magnetostriction. The magnetostriction of grain-oriented electrical steel was more sensitive to the applied compressive stress than other steels. The weight placed on the test specimen to prevent the deformation becomes very important. According to the test, Case 2 was thought better than Case 1 and Case 1was better than Case 3.

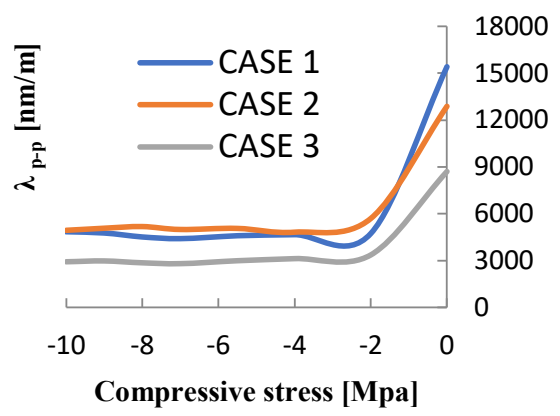

a) Comparison of $\lambda_{z-p}$

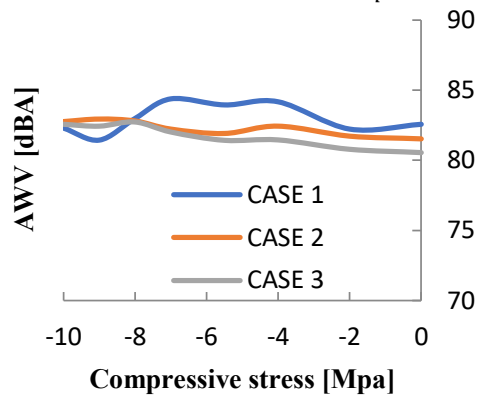

c) Comparison of AWV

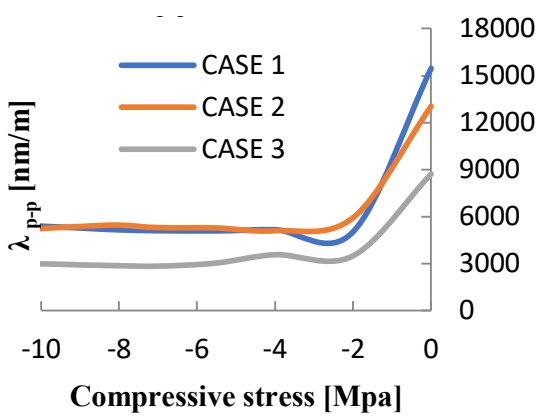

b) Comparison of $\lambda_{p-p}$

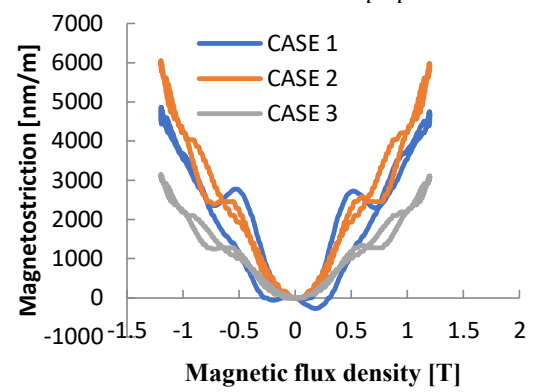

d) Comparison of butterfly loop under $-4 \mathrm{MPa}$

Fig. 4. Comparison of magnetostriction parameters on $1.2 \mathrm{~T}$

\section{Conclusions}

The influence of the weight placed on the test specimen on the magnetostriction test results is fully considered in this paper and find the optimal measurement method of magnetostriction measurements under an externally compressive stress, which improves the accuracy and reliability of magnetostriction measurement effectively.

In the case of zero stress, the magnetostriction parameters of the grain-oriented electrical steel, $\lambda_{z-p}[\mathrm{~nm} / \mathrm{m}], \lambda_{p-p}[\mathrm{~nm} / \mathrm{m}]$ and AWV [DBA], was decrease with increase of the weights placed on the test specimen. So, no weight, except the optical target, shall be placed on the test specimen when the magnetostriction measurement at zero stress.

In the case of under an externally compressive stress, a weight should be placed on the test specimen to prevent a deformation of test specimen. The selection of the weight placed on the test specimen to prevent the deformation becomes very important. The selected weight is too small, the deformation of the test specimen still occurs, and which cause the magnetostriction measurement offset.

It is the most accurate measurement when the placed weight can prevent the deformation of test specimen and at the same time ensure the free movement of magnetic domain of grain-oriented electrical steel. The optimal weight placed on the test specimen needs to be determined according to different brand and thickness of test specimen.

When the weight placed on the test specimen is very large, the free movement of the magnetic domain in grain-oriented electrical steel will be greatly limited, resulting in the magnetostriction, $\lambda_{z-p}[\mathrm{~nm} / \mathrm{m}], \lambda_{p-p}[\mathrm{~nm} / \mathrm{m}]$ and AWV [DBA] significant decrease, like Case 3 . At this case, the magnetostriction data can't reflect the magnetostriction properties of grain-oriented electrical 
steel.

Magnetostriction of grain-oriented electrical steel plays an important role in the simulation and design of transformer and reactor because magnetostriction is the main reason to make the vibration and acoustic. Accurate measurement of magnetostriction under the compressive stress is good for product design and simulation.

\section{Acknowledgements}

Science and Technology Project of the State Grid Corporation of China Headquarters: In-depth Research and Application of the Key Technology of Noise Reduction for Single-Column UHV Shunt Reactors (5200-201919104A-0-0-00).

\section{References}

[1] Z. Cheng, N. Takahashi and B. Forghani, Modeling and Application of Electromagnetic and Thermal Field in Electrical Engineering, Beijing: Science Press, 2020.

[2] A. J. Moses, "Relevance of microstructure and texture to the accuracy and interpretation of 1 and 2 directional characterisation and testing of grain-oriented electrical steels", International Journal of Applied Electromagnetics and Mechanics, Vol. 55, No. S1, pp.3-13, 2017, https://doi.org/10.3233/JAE-172252

[3] "Electrical steel-methods of measurement of the magnetostriction characteristics by means of single sheet and Epstein test specimen," IEC TR 62581, 2010.

[4] J. Kobori, Y. Takahashi, and K. Fujiwara, "The international round robin test of magnetostriction measurement of grain-oriented electrical steel by means of a single sheet tester and an optical sensor," Journal of Magnetism and Magnetic Materials, Vol. 513, p. 166541, Nov. 2020, https://doi.org/10.1016/j.jmmm.2020.166541

[5] "Magnetic materials - Part 16: Methods of measurement of the magnetic properties of Fe-based amorphous strip by means of a single sheet tester," IEC 60404-16, 2018.

[6] S. Siebert, J. Kobori, K. Fujiwara, and P. Klimczyk, "Standardization of the method of magnetostriction measurement of grain-oriented electrical steel strip and sheet," Journal of Magnetism and Magnetic Materials, Vol. 504, p. 166644, Jun. 2020, https://doi.org/10.1016/j.jmmm.2020.166644

[7] M. Mizokami, M. Yabumoto, H. Mogi, and T. Kubota, "Magnetostriction of grain-oriented electrical steel and noise of transformers," in 24th Conf. on Properties and Applications of Magnetic Materials, 2005.

[8] B. Weiser, H. Pfutzner, and J. Anger, "Relevance of magnetostriction and forces for the generation of audible noise of transformer cores," IEEE Transactions on Magnetics, Vol. 36, No. 5, pp. 3759-3777, 2000, https://doi.org/10.1109/20.908346

[9] T. Nakase, M. Nakano, K. Fujiwara, and N. Takahashi, "Measuring system for magnetostriction of silicon steel sheet under AC excitation using optical methods," IEEE Transactions on Magnetics, Vol. 34, No. 4, pp. 2072-2074, Jul. 1998, https://doi.org/10.1109/20.706800

[10] G. C. Eadie, "The effects of stress and temperature on the magnetostriction of commericial silicon-iron grain-oriented electrotechnical steel strip," Journal of Magnetism and Magnetic Materials, Vol. 26, No. 1-3, pp. 43-46, Mar. 1982, https://doi.org/10.1016/0304-8853(82)90112-3

[11] M. Fujikura. S. Arai, H. Mogi, M. Yabumoto, and T. Kubota, "Analysis of magnetostriction reduction of magnetostriction reduction of grain-oriented electrical steel," in 7th International Workshop on 1 and 2 Dimensional Magnetic Measurement and Testing, pp. 23-29, 2003. 